\title{
An Analysis of Outpatients' Perceived Service Quality and Satisfaction in Selected Private Hospitals of Kathmandu*
}

\author{
Paridhi Pathak ${ }^{1}$
}

\begin{abstract}
Patients' perceptions about health services, especially about service quality, are becoming increasingly important. It might shape confidence and subsequent behaviors with regard to their choice and usage of the available health care facilities. The study examines the primary satisfaction with a private hospital experience and estimate the effect that each of these construct will have on future behavioral intensions. More specifically, it measures patient's perceptions of service quality and assesses the dimensions of service quality exert strongest influence on customer satisfaction. The study is based on primary data, which collected from outpatients in the ten selected private hospitals of Kathmandu valley via self-administered and structured questionnaire survey. Convenience sampling method is applied for the study that constituted of 200 outpatients from private hospitals. The present study is based on the SERVPREF model in which independent variables are tangibles, responsiveness, empathy, reliability and assurance whereas the dependent variable is overall satisfaction of the patients. The findings of this study show that 72 percent of the respondents are satisfied with the overall quality of the hospitals; 5 percent are dissatisfied and 18 percent are neutral. It also reveals that satisfaction of the outpatients is irrespective of their genders, age, income level and education. Among all constructs the most positive perceptions are seen in the assurance dimension of the hospitals followed by tangibles, responsiveness, reliability and empathy. Additionally, it is seen that responsiveness dimension is the most strongly correlated dimension with overall satisfaction; while the other dimensions have weak to moderate positive correlation. Overall, a positive relationship is found between patient's perception of service quality and their satisfaction.
\end{abstract}

Keywords: patient satisfaction; private hospitals; SERVPREF model; primary Survey and descriptive statistics

The earlier version of this paper was presented in (i) International Conference on Business, Society and Governance: Emerging Management Paradigm on 27 February 2017 in Pokhara, Nepal and (ii) International Conference on Emerging Trends and Issues in Management on 1 June 2017 in Kathmandu, Nepal.

1 The researcher is indebted to Prof. Dr. Kundan D. Koirala (former dean of Tribhuvan University, Faculty of Management) and Dr. Ram Kumar Phuyal (Associate Professor, CEDA, Tribhuvan University) for their valuable insights and commendable supports in building this paper. She would also like to extend her gratefulness to Mr. Sohan B. Khatri (Faculty member of AIM) for his suggestion and guidance in the course of undertaking this research. 


\section{Introduction}

The global medical industry is one of the world's fastest growing industries, absorbing over $10 \%$ of gross domestic product of most developed nations. It constitutes of broad services offered by various hospitals, physicians, nursing homes, diagnostic laboratories, pharmacies and ably supported by related suppliers. Service providers are progressively facing a wide range of challenges, associating with demands for greater efficiency, better quality, and lower costs.

Nepal has its own indigenous system of medicine which remained mainstream health system until initial part of modern Nepal. The search of more efficient health system has paved the road for western medicine or allopathic system of medicine which is also known as the modern era for health. 1889 AD was the landmark for this with the establishment of Bir Hospital by Nepal government to provide health services to common people. In recent years, we have seen an increasing interest in private hospital services, as standards of living has changed and there is a demand for better medical care to improve lifestyles. Moreover, patients are becoming more open to competitive advances and more familiar with health care services, and, thus to ensure patients has a long-term commitment to the hospital. Many hospitals look beyond satisfaction to developing loyalty in order to reduce the perceived risk of using the service. Therefore, improving the quality of medical care services has become a primary concern for patients, and, in order to provide better service to patients, service quality has become increasingly important for hospitals in respect of satisfying and retaining patients.

Nonetheless, measuring the quality of intangible service products has become a great challenge for managers and technical staffs in the health services industry. Patient satisfaction or dissatisfaction is a complicated phenomenon that is linked to patient expectations, health status, personal characteristics as well as health system characteristics. However, patient satisfaction as an indicator of quality of healthcare has evolved as an outcome measure. In addition, patient satisfaction surveys are being increasingly identified to be established yardsticks to measure success of the service delivery system functional at hospitals.

In Nepal, according to the Nepal Living Standard Survey (NLSS_2010-2011), about 63 percent of visitors go to private health institutions, the remaining go to government institutions. Of all facilities in the country, private clinic is attended by majority of sick people (28\%). Others go to pharmacy (25\%), hospital/public health 
center $(14 \%)$, sub-health post $(8 \%)$, health post $(8 \%)$, private hospital $(5 \%)$ and others (7\%). In Kathmandu valley alone there are 67 private hospitals operating in various capacities as per the Report on Census of Private Hospitals in Nepal, 2013.

Outpatient department (OPD) is the first point of contact of the hospital with patients and serves as the shop window to any healthcare service provided to the community. The care in the OPD is believed to indicate the quality of services of a hospital and is reflected by patients' satisfaction with the services being provided. The overall experiences of the patients involve a number of factors such as doctor's competence, his interaction with the patients, behavior of the paramedical staff, various facilities offered by the hospital, behavior of support staff and overall hygiene and ambience of the hospital.

Study on effect of patients perceived service quality and their satisfaction in health care industry is not so commonly done in our country. Thus, this study shall generate new conclusions to enrich the existing literatures on health care service quality in Nepal. The private health care providers of Nepal are currently competing on either prices or outflow of promotional strategies to maintain existing customers and attract new ones. However, regulators and industry experts have expressed worry about the fact that the intense competition is not being matched by the necessary improvements in service quality.

In this respect, the study provides a better understanding of the satisfaction level among patients within Kathmandu's private hospitals and how its managers can improve their service qualities. Specific objectives of this research are to examine the overall satisfaction level among out patients within Kathmandu's selected private hospitals, identify which service quality attributes are more preferred by the patients, and study the outpatients' perceptions of the service quality in private hospitals of Kathmandu. The study is very timely and contributes to knowledge on service quality and customer satisfaction and it is expected to be of great benefit to operators, regulators as well as patients.

This study is organized as follows; section one is general background and introduction, section two presents a review of the literature, section three describes the methodology, Section four provides analysis of data and section five provides concluding remarks. 


\section{Review of Literature}

Carson et al. (1998) concludes that perceived quality is the single most important variable influencing consumers' perceptions of value which affects their intention to purchase. It states that because patients are often unable to assess the technical quality of medical services accurately, functional quality is the primary determinant of their perceptions of quality. Similarly, Yoo (2005) has conducted a study in the service quality at hospitals using SERVPERF in South Korea and concluded that the major determinants of customer satisfaction at clinics are aspects related with 'tangibles' and 'empathy' dimensions of services and it has a significant effect on word of mouth and patronage for health service providers. Irfan et al. (2012) have conducted a research to study the patient satisfaction and service quality of public hospitals in Pakistan which has concluded that quality is one of the key parameter in order to measure the performance of a product or service and ultimately it refers to organizational performance. Amin et al. (2013) have studied the hospital service quality and its effects on patient satisfaction and behavioral intention. The results indicate that managers should use the perceived service quality and customer satisfaction as mechanisms to build strategy that will increase loyalty among the present customers. Similarly, Shirzadi et al. (2016) have conducted a national study on the factors affecting the quality of hospital services from the patients and their companions' point of view which has concluded that the effect exerted by the quality factors are very significant.

A research on the patients' perspective of service quality of hospital outpatient departments in Tehran, Iran have been conducted by Zarei et al. (2015) which has revealed that physician consultation, information provided to the patient, and the physical environment of the clinic are the three determining factors of the quality of outpatient services. Yousapronpaiboon et al. (2013) have studied the out-patient service quality perceptions in private Thai hospitals, and concluded that SERVQUAL's five latent dimensions have a significant influence on overall service quality. Responsiveness has most influence; followed by empathy, tangibles, assurance; and finally reliability.

The study conducted by Ramez (2012) on the patients' perception of health care quality, satisfaction and behavioral intention: an empirical study in Bahrain has revealed that responsiveness, empathy and tangible dimensions have the largest influence on the overall service quality. Positive and significant relationships are found between overall service quality (OSQ), patients' satisfaction (SAT), and their 
behavior intention (BI).Similarly, Aljoudimi et al. (2015) have studied the service quality toward patient satisfaction the moderating role of time and efforts in public hospitals in Tripoli, Libya which has revealed that the time and effort do not moderate the relationship between service quality dimensions and patient satisfaction. The study contributes to the further development of studies in service quality, perceived value and patient satisfaction in healthcare environment.

A comparative study on the impact of health service quality on patients' satisfaction over private and public hospitals has been conducted by Zamil et al. (2012) in Jordan. It has revealed that there is an impact of the health service quality on patient's satisfaction, a significant statistical difference of the impact between public and private hospitals sector which is greater in the private hospitals. Alghamdi (2014) has studied to explore the impact of service quality perception on patient satisfaction in government hospitals in southern Saudi Arabia. The finding of this research is that patient satisfaction is influenced by health service quality, with the empathy dimension as the greatest influence on patient satisfaction. Similarly, Le and Fitzgerald (2014) have conducted a study by applying the SERVPERF scale to evaluate quality of care in two public hospitals at Khanhhoa province, Vietnam. The finding of this research shows that patient satisfaction is influenced by health service quality, with the empathy dimension as the greatest influence on patient satisfaction.

Although it is widely acknowledged all over the world that there is a need for understanding the impact of service quality of hospitals and its effect on patients' satisfaction as it is key to any health service provider, very little research in this area exists in Nepal . Previous researches conducted internationally do not clearly address the research question in the context of Nepal's private hospitals. Thus, this study attempts to minimize this existing research gap.

\section{The Methodology}

In this study, the researcher has employed the SERVPERF model to analyze the service quality of the private hospitals as perceived by the outpatients and linking it with their satisfaction. The SERVPERF model argues that only perception is sufficient for measuring service quality therefore expectations should not be involved in measurement. In the service quality scale (SERVQUAL), SERVPERF model is the performance component to measure five dimensions in many empirical studies on service quality. Zhou (2004) has demonstrated that performance attributes are much stronger as predictor of customer satisfaction 
74 Pathak: An Analysis of Outpatients' Perceived Service Quality

more than expectation comparatively and SERVPERF is useful tool to regard the effects of individual service quality dimensions on satisfaction.

Methodologically, SERVPERF scale represents marked improvement over the SERVQUAL scale with the higher reliability and time saving. The number of items decreases from 44 questions to 22 questions and it is able to explain the relationship between service quality and customer satisfaction by using single-item scale. In this model, five dimensions are tested and evaluated on how they influence on customer satisfaction. Ideally, total variance explained by five components and all components will support for customer satisfaction evaluation. In many researches, five dimensions including 22 questions are explained by four components that are used to test hypotheses and decide which component support for customer satisfaction evaluation.

\subsection{The Conceptual Model}

The study conducted by Zamil et al. (2012) has been considered as one of the basic paper to draft the conceptual framework for this study which is depicted as below: 


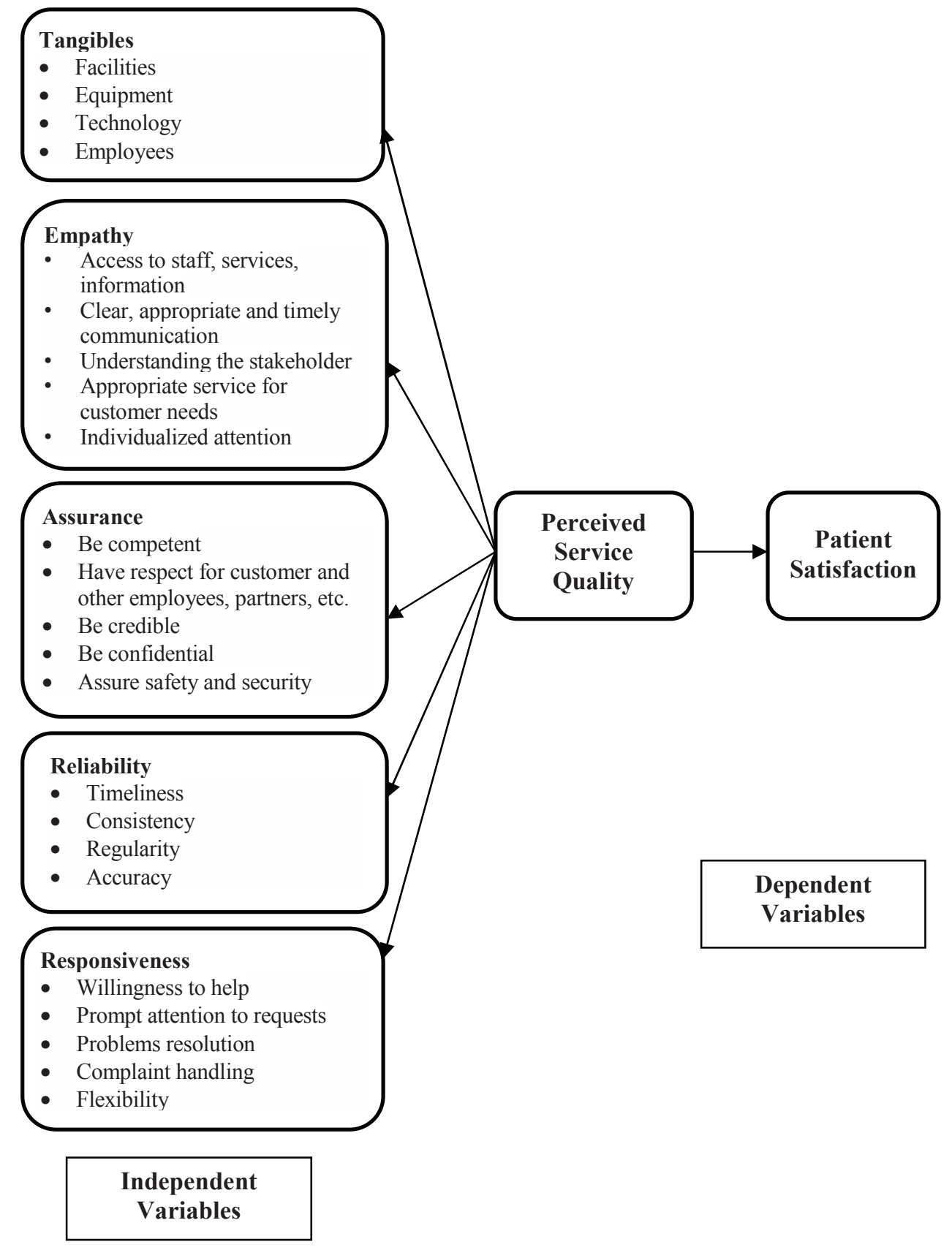

Figure 1: Conceptual framework 
The framework below shows proposed framework to serve as foundation of this study. Purpose of this study is to examine how tangibles, empathy, assurance, reliability, and responsiveness, which are the independent variables, can bring impact on the dependent variable, patients' satisfaction towards the service quality at private hospitals of Kathmandu. Each of these independent variables and the indicators used to assess them can be summarized as follows:

1) Tangibles: The indicators of this variable, which is related to the physical facilities, appearance of personnel and the equipment of the hospital, are "Neat appearance and Neat appearance of polyclinic service", "Professional appearance and Modern equipment".

2) Empathy: The indicators of this variable, which is related to the caring, individualized attention the firm provides its customers, are "Given individual attention", "Convenient consultation hours", and "Understand the specific needs of patient".

3) Assurance: The indicators of this variable, which is related to the knowledge and courtesy of employees and their ability to inspire trust and confidence, are "Constantly courteous", "Able to instill confidence in patient", "Having the knowledge to answer patients' questions" and "ability to handle patients' problems".

4) Reliability: The indicators of this variable, which are related to the ability to perform the promised service dependably and accurately, are "a sincere interest in solving problem", "Maintains error-free records", and "Providing services as promised".

5) Responsiveness: The indicators of this variable, which are related to the willingness to help customer and provide prompt service, are "Offering prompt services to patients" "Responding quickly", and "Willing to help patients".

\subsection{The Data}

In this study, both primary and secondary data are used. At the initial phase for the purpose of developing theoretical framework, the data collection procedure is secondary. The secondary sources of data used are internet, books, journals, newspaper and articles. As the study is based on primary data, the first hand data are gathered with the help of questionnaire. The questionnaire is structured and administered personally by the researcher with the respondents in a face-to-face situation. The survey was conducted in 2016 wherein the population considered are all the private hospitals operating within Kathmandu valley having OPD services. The private hospitals are categorized in five quartiles based on the number of beds namely hospitals with less than 50 beds, $50-100$ beds, $100-200$ beds, $200-300$ beds 
and more than 300 beds. Two hospitals in each category and a total of 10 private hospitals have been selected as samples using convenience sampling method. From each of the hospitals 20 outpatients are purposively selected as sample respondents, and the total size of the sample is 200 .

The data used for this study are obtained using a structured survey questionnaire designed to evaluate perceptions of the outpatients on service quality and linking it to their satisfaction. The questionnaire is designed to reflect patient satisfaction with the service delivery of private hospitals. The questions used in the survey are closed ended and a 5 point Likert scale to evaluate the level of satisfaction with the service quality provided by respective operators. The structured questionnaires are based on the five dimensions of service quality (tangibility, assurance, reliability, responsiveness and empathy) and this research has further used the five point Likert scale from 1 strongly disagree to 5 strongly agree to calculate the overall satisfaction. Random sampling approach is used to identify the respondents for the study.

\subsection{Analysis Methods}

For data management, SPSS 20 software is used. The collected data are logically and systematically recorded using SPSS software and analysis is done as per the requirement of study. Besides, different statistical data analysis techniques have been employed to test the ten hypothesized relationship among service. The positive relationship means that the higher/lower service quality dimensions is evaluated, the higher/lower level of patient satisfaction achieved.

More specifically, the descriptive and inferential analysis is used for analyzing the data. Central tendency, frequency table, chart, graph, and dispersion are used for descriptive analysis whereas hypothesis testing, chi-square test, correlations and regression analysis are conducted. The following null hypotheses are tested:

$\mathrm{H}_{01}$ : There is no significant relationship between tangibles of the hospital and overall patient's satisfaction.

$\mathrm{H}_{02}$ : There is no significant relationship between empathy of the hospital and overall patient's satisfaction.

$\mathrm{H}_{03}$ : There is no significant relationship between reliability of the hospital and overall patient's satisfaction.

$\mathrm{H}_{04}$ : There is no significant relationship between responsiveness of the hospital and overall patient's satisfaction.

$\mathrm{H}_{05}$ : There is no significant relationship between assurance of the hospital and overall patient's satisfaction. 


\section{Results and Discussions}

The study has employed descriptive analysis for describing the data and correlation and regression analysis among other statistical tests to analyze data. The results from the statistical tests of significance are presented and analyzed in the subsequent sections.

\subsection{Descriptive Statistics}

The frequency distribution and percentage of the demographic variables (gender, age group, occupation, education level, monthly income and place of origin of the respondents) are depicted in the table below. The study population is described along with the measures of central tendency and dispersion of the variables that are under study.

Table 1. Descriptive statistics

\begin{tabular}{llll}
\hline Variable & Classification of Variable & Frequency & Percent (\%) \\
\hline \multirow{2}{*}{ Gender } & Male & 112 & 56 \\
& Female & 88 & 44 \\
Age group & $18-25$ & 33 & 16.5 \\
& $26-40$ & 93 & 46.5 \\
& $41-60$ & 55 & 27.5 \\
& 61 and above & 19 & 9.5 \\
& Employed & 104 & 52.0 \\
Occupation & Student & 9 & 4.5 \\
& Working Student & 18 & 9.0 \\
& Business/Self employed & 48 & 24.0 \\
& Unemployed & 15 & 7.5 \\
& Others & 6 & 3.0 \\
Education Level & Masters and above & 81 & 40.5 \\
& Bachelors & 88 & 44.0 \\
& Intermediate & 20 & 10.0 \\
& SLC or below & 11 & 5.5 \\
& Below 10,000 & 12 & 6.0 \\
Income level (NRs.) & 25001-25000 & 48 & 24.0 \\
& 50001-100000 & 63 & 31.5 \\
& 100001 and above & 35 & 17.5 \\
Place of Origin & None & 24 & 12.0 \\
& Kathmandu Valley & 18 & 9.0 \\
& Outside Kathmandu Valley & 99 & 49.5 \\
& & & 50.5 \\
\hline
\end{tabular}


Results show that among the total respondents, $56 \%$ are male and $44 \%$ female. The study includes respondents of age 18 and above. In the sample chosen, most of the respondents (46\%) belong to age group 26-40 and the age group 61 and above contains least number of respondents $(9.5 \%)$ to this research. Another categorization of the respondents is based on their profession. Among 200 outpatients surveyed, more than half $(52 \%)$ are employed in some kind of professions while $24 \%$ are engaged in business activity or are self-employed. The sample also consists of few students $(4.5 \%)$, some working students $(9 \%)$ while $7.5 \%$ respondents are seen to be unemployed. The maximum number of respondents $(44 \%)$ in the research group have bachelor's degree as their highest educational level whereas very few $(5 \%)$ of respondents have below SLC level education. The count of respondents completing master's degree is also quite high in number comprising of $40.5 \%$ of the sample of 200 . For most of the respondents, monthly salary falls under the category of " $25000-50000$ ". Finally, the proportion of respondents from inside and outside Kathmandu valley is seen to be almost equal with $51 \%$ respondents are originally from outside Kathmandu valley while $49 \%$ from inside the Kathmandu valley.

The mean of the overall satisfaction level with the quality of services provided by the hospitals is seen as 3.75 , here 1 being very dissatisfied and 5 being very satisfied. This means that on an average the outpatient that are sampled are "satisfied" with what the service quality the hospital has offered. As per the rank given by the respondents to the five different service attributes with 1 being most important and 5 being the least important, the patients feel that "competent and concerned hospital staff "is the most important factor followed by up-to-date technology, specialization service availability, neat and clean ambience and finally price. We can see that price or affordability is important but when it comes to health care it is something that people feel is less important when compared to the other factors like, medical staff, technology and diversity of services.

Overall, the mean analysis shows that the average of Assurance Score is the highest i.e. 4.21 which means that the respondents show the most positive perception towards the assurance factors provided by the hospitals followed by tangibles, responsiveness, reliability and empathy .

\subsection{Correlation Analysis}

This section shows how variables are related to each other. Correlation analysis between age and overall satisfaction level shows that Pearson Correlation between these variables is -0.018 , which shows that there is a very weak negative correlation between age of the respondents and their overall satisfaction level. Similarly, there is a weak but positive correlation (0.063) between gender and 
overall satisfaction level of the patients; a negative and a weak correlation (-0.128) between occupation of the respondents and their overall satisfaction level; a weak negative correlation $(-0.143)$ between their monthly income of the respondents and their overall satisfaction level and a weak positive correlation (0.04) is seen between education and their overall satisfaction level.

About the relationship between the five dimensions of quality and the overall satisfaction level, a positive and weak correlation can be seen between the average score of the tangibles and the overall satisfaction level of the outpatients. a positive and moderate correlation between the average score of the empathy and the overall satisfaction; a moderate positive correlation between the average score of the assurance and satisfaction; a moderate positive correlation (0.493) between the average score of the reliability and satisfaction; and a strong positive correlation $(0.725)$ is seen between the average score of the responsiveness and the overall satisfaction level of the outpatients. The P-value (0.000) is also less than significance value $(0.05)$ in all five cases, thus the study shows a significant relationship between five quality dimensions of service quality of the hospitals and overall satisfaction level of the patients.

Table 2. Summary of result of hypothesis test using correlation analysis

\begin{tabular}{lllll}
\hline Hypothesis $\left(\mathbf{H}_{\mathbf{0}}\right)$ & Relationship & $\begin{array}{l}\text { Pearson's } \\
\text { Correlation }\end{array}$ & $\begin{array}{l}\text { Sig } \\
(\mathbf{P}-\text { Value) }\end{array}$ & Remarks \\
\hline $\mathrm{H}_{01}$ & Tangibles and OS & 0.239 & 0.001 & $\begin{array}{l}\text { Reject null } \\
\text { hypothesis }\end{array}$ \\
$\mathrm{H}_{02}$ & Empathy and OS & 0.478 & 0.000 & $\begin{array}{l}\text { Reject null } \\
\text { hypothesis }\end{array}$ \\
$\mathrm{H}_{03}$ & Assurance and OS & 0.306 & 0.000 & $\begin{array}{l}\text { Reject null } \\
\text { hypothesis }\end{array}$ \\
$\mathrm{H}_{04}$ & Reliability and OS & 0.493 & 0.000 & $\begin{array}{l}\text { Reject null } \\
\text { hypothesis }\end{array}$ \\
$\mathrm{H}_{05}$ & $\begin{array}{l}\text { Responsiveness } \\
\text { and OS }\end{array}$ & 0.725 & 0.000 & $\begin{array}{l}\text { Reject null } \\
\text { hypothesis }\end{array}$ \\
\hline
\end{tabular}

\subsection{Regression Analysis}

A simple linear regression as the model has been used in this research to predict the relationship between the variables. The following regression function explains the nature and strength of relationship between the dependent and independent variables as envisaged in the conceptual framework:

$$
\begin{aligned}
& \text { Overall Satisfaction }=0.254 \mathrm{TAN}+2.745 \ldots \text {. (i) } \\
& \text { Overall Satisfaction }=0.446 \mathrm{EMP}+2.133 \ldots \text { (ii) } \\
& \text { Overall Satisfaction }=0.305 \mathrm{ASS}+2.464 \ldots \text { (iii) }
\end{aligned}
$$




$$
\begin{aligned}
& \text { Overall Satisfaction }=0.446 \text { REL }+1.617 \ldots \text { (iv) } \\
& \text { Overall Satisfaction }=0.446 \text { RES }+2.133 \ldots \text { (v) }
\end{aligned}
$$

The results show that the overall satisfaction of the outpatients with the quality of the hospitals is predicted by the outpatient's perception of the five service quality dimensions namely Tangibles $(\beta 1=0.254, p<0.01)$, Empathy $(\beta 2=0.446, p<0.01)$, Assurance $\left(\beta_{3}=0.305, \mathrm{p}<0.01\right)$, Reliability $\left(\beta_{4}=0.576, \mathrm{p}<0.01\right)$ and Responsiveness $\left(\beta_{5}=0.922, \mathrm{p}<0.01\right)$.

Here, the coefficients or the beta value for all dimensions explains how much is the change in the dependent variable vis a vis change in the predictor variables. The first component is Tangible and its coefficient value is 0.254 . It means that a unit increases or decreases in Tangibles, it leads to an increase or decrease in customer satisfaction by 0.254 unit. Similarly, a unit increases or decreases in empathy leads to an increase or decrease in customer satisfaction by 0.446 unit; a unit increases or decreases in assurance leads to an increase or decrease in customer satisfaction by 0.305 unit. Likewise, a unit increases or decreases in reliability, it leads to an increase or decrease in customer satisfaction by 0.576 unit. Here the beta value for responsiveness dimensions is the highest i.e. 0.922 . Thus, it is very essential that the hospital management pay focus on this dimension as it exerts strong effect on the overall satisfaction level of the patients.

\begin{tabular}{|c|c|c|c|c|c|c|c|}
\hline $\begin{array}{l}\text { Hypothesis } \\
\text { (H0i) }\end{array}$ & Effects & $\mathbf{R} 2$ & $\begin{array}{l}\text { Constant } \\
\text { (B0) }\end{array}$ & $\begin{array}{l}\text { Coefficient } \\
(\beta i)\end{array}$ & t-stat & Sig & Remarks \\
\hline $\mathrm{H} 01$ & $\begin{array}{l}\text { TAN } \rightarrow \\
\text { OS }\end{array}$ & 0.057 & 2.745 & 0.254 & 3.463 & 0.000 & Reject \\
\hline H02 & $\begin{array}{l}\mathrm{EMP} \rightarrow \\
\mathrm{OS}\end{array}$ & 0.228 & 2.133 & 0.446 & 7.653 & 0.000 & Reject \\
\hline H03 & $\begin{array}{l}\mathrm{ASS} \rightarrow \\
\mathrm{OS}\end{array}$ & 0.093 & 2.464 & 0.305 & 4.515 & 0.000 & Reject \\
\hline H04 & $\begin{array}{l}\mathrm{REL} \\
\rightarrow \mathrm{OS}\end{array}$ & 0.243 & 1.617 & 0.576 & 7.980 & 0.000 & Reject \\
\hline H05 & $\begin{array}{l}\mathrm{RES} \\
\rightarrow \mathrm{OS}\end{array}$ & 0.525 & 0.313 & 0.922 & 14.804 & 0.000 & Reject \\
\hline
\end{tabular}

Table 3. Regression analysis and result of hypothesis test

Overall, a significant relationship is seen between the overall satisfaction and all five dimensions of quality as the $p$ values are less than the significance level in all five cases and, therefore, significant relationship exists between these five constructs of quality and the overall satisfaction of the respondents. 


\section{Concluding Remarks}

The relationship between service quality and customer satisfaction has been the concern of many previous studies in the context of service industry. To measure it, present study aims to investigate the relationship between perceived service quality and patient satisfaction in private hospitals of Kathmandu Valley. The finding of this study is coherent with similar studies done in different parts of the world and supports the finding that the perception towards service quality dimensions does have a significant effect on customer satisfaction. Notwithstanding, that this research findings provide some new insights in the topic but these findings should be viewed in the light of some limitations like sample size, location, type of hospital, variables selection including response errors.

The first objective of this research is to study about the overall satisfaction level among out patients within Kathmandu's private hospitals. The results show that the mean score of the overall satisfaction level of patients is 3.75 , which entails that a majority of outpatients are satisfied with the service quality of the private hospitals. With regards to the most preferred service quality factors, the patients feel that "competent and concerned hospital staff"is the most important factor followed by up-to-date technology, specialization service availability, neat and clean ambience and price. It is known that price or affordability is important in itself but when it comes to health care, it is something that people feel is less important when compared to the other factors like, medical staff, technology and diversity of services.

It is also found that satisfaction of the outpatients is irrespective of their genders, age, income level and education. Nonetheless, patient's satisfaction depends on their perceived service quality of the five constructs i.e. tangibility, empathy, assurance, reliability and-responsiveness. Among all constructs, the outpatient's have most positive perceptions of the assurance dimension of the hospitals followed by tangibles, responsiveness, reliability and empathy.

Finally, it is seen that there is a positive relationship between perception of service quality and satisfaction. Obtaining satisfaction of patients depends largely on ensuring that the hospital maintains high service quality standards. Enhancing quality mechanisms has significant effect on the level of customer satisfaction. Hence, from the result of the study, it can be concluded that service quality has significant positive impact on patient's perception of the service quality in selecting health service provider and becoming loyal to its operator.

In sum, we can inclusively infer that patients of Kathmandu's private hospital industry are satisfied as per their perceptions on the service quality; however, a lot can be done to make it better. It warns managers to focus on patients expectations. 
They should gain more information about patient's attitude and prepare plans to improve the weak points. It is highly desirable that private hospitals give caring and individualized attention to its patients. Second important attributes is "improving medical condition". Hospital must provide the environment that builds trust in patients and their families. Comfortable waiting room, good quality of drug in pharmacy, punctuality of doctors, nursing services and good reputation of hospital, expenses rationality, short-waiting time and politeness of doctors are the important service attributes preferred by the patients. These attributes are highly desirable. Managers must need to invest more on these attributes to increase customer satisfaction.

\section{References}

Alghamdi, F. S. (2014). The impact of service quality perception on patient satisfaction in Government hospitals in Southern Saudi Arabia. Saudi Medical Journal, 35(10), 1271-1273.

Aljoudimi, Y. I., Rejab, I. B., \& Mohamed, Z. B. (2015). Service quality toward patient satisfaction the moderating role of time and efforts in public hospitals in Tripoli, Libya. International Journal of Managerial Studies and Research, 3(6), 97-116.

Amin, M. (2013). Hospital service quality and its effects on patient satisfaction and behavioural intention. Clinical Governance: An International Journal, 18(3), 238-254.

Carson, P. P., Carson, K. D., \& Roe, C. W. (1998). Toward understanding the patient's perception of quality. The Health Care Supervisor, 16(3), 36-42.

Irfan, S. M., Ijaz, A., \& Farooq, M. M. (2012). Patient satisfaction and service quality of public hospitals in Pakistan: an empirical assessment. Middle-East Journal of Scientific Research, 12(6), 870-877.

Le, P., \& Fitzgerald, G. (2014). Applying the SERVPERF scale to evaluate quality of care in two public hospitals at Khanh Hoa Province, Vietnam. Asia Pacific Journal of Health Management, 9(2), 66.

NLSS. (2011). Nepal Living Standards Survey Report 2011, (Vol. I), Kathmandu: Central Bureau of Statistics.

Ramez, W. S. (2012). Patients' perception of health care quality, satisfaction and behavioral intention: An empirical study in Bahrain. International Journal of Business and Social Science, 3(18), 131-141. 
Shirzadi, S. M., Raeissi, P., Nasiripour, A. A., \& Tabibi, S. J. (2016).Factors affecting the quality of hospital hotel services from the patients and their companions' point of view: A national study in Iran. Journal of Research in Medical Sciences: The Official Journal of Isfahan University of Medical Sciences, 21(2), 46.

Yoo, S. (2005). Service quality at hospitals. Asia Pacific Advances in Consumer Research Journal, 6(1), 188-193.

Yousapronpaiboon, K., \& Johnson, W. C. (2013). Out-patient service quality perceptions in private Thai hospitals. International Journal of Business and Social Science, 4(2), 57-66.

Zamil, A., Areiqat, A., \& Tailakh, W. (2012).The impact of health service quality on patients' satisfaction over private and public hospitals in Jordan. International Journal of Marketing Studies, 4(1), 123-137.

Zarei, E., Daneshkohan, A., Pouragha, B., Marzban, S., \& Arab, M. (2015). An empirical study of the impact of service quality on patient satisfaction in private hospitals, Iran. Global Journal of Health Science, 7(1), 1-9.

Zhou, L. (2004). A dimension-specific analysis of performance-only measurement of service quality and satisfaction in China's retail banking. Journal of Services Marketing, 18(7), 534-546. 